\title{
Laboratory scale study on the effect of feeding quinoa (Chenopodium quinoa) as meal on serum biochemistry of broiler
}

Samina Mustafa ${ }^{1}$, Zainab Tariq ${ }^{1}$, Ayesha Riaz ${ }^{*}$, Muhammad Shareef Masoud $^{2}$, Muhammad Ahsan Riaz ${ }^{3}$, Madiha Ilyas ${ }^{4}$, Sadaf Nazar ${ }^{1}$, Anwar ul Haq ${ }^{5}$ and Zahida Sabir ${ }^{1}$

1. Department of Zoology, GC Women University Faisalabad-Pakistan

2. Department of Bioinformatics and Biotechnology, GC University Faisalabad-Pakistan

3. Department of Environmental Sciences \& Engineering, GC University Faisalabad-Pakistan

4. Department of Home Economics and Food Nutrition, GC Women University Faisalabad-Pakistan

5. Veterinary Officer, Livestock Department, Government of Punjab-Pakistan

*Corresponding author's email: Ayeshariazrana@gmail.com

Citation

1Samina Mustafa, Zainab Tariq, Ayesha Riaz, Muhammad Shareef Masoud, Muhammad Ahsan Riaz, Madiha Ilyas, Sadaf Nazar, Anwar ul Haq and Zahida Sabir. Laboratory scale study on the effect of feeding quinoa (Chenopodium quinoa) as meal on serum biochemistry of broiler. Pure and Applied Biology. Vol. 8, Issue 4, pp2326-2332. http://dx.doi.org/10.19045/bspab.2019.80179

Received: 31/01/2019 Revised: 24/07/2019 Accepted: $12 / 08 / 2019$

Online First: 23/08/2019

\section{Abstract}

Quinoa is a pseudo-cereal with the variety of vitamins, minerals contents, important proteins, essential unsaturated fatty acids and carbohydrates with less glycemic index. The current study was designed to evaluate the effects of quinoa seed meal on serum biochemistry of broiler birds. Seventy (one day old) chicks were raised and divided into groups $(n=6)$ with ten birds $(n=10)$ in each group. The total duration of the experiment was 42 days and all the birds were fed with commercially available feed from market (Starter)from day 1 to day 14. From day 15 to day 42 all the birds in group 1 were fed with the dietcontaining $50 \mathrm{~g} / \mathrm{kg}$ quinoa seeds meal. Group 2 birds were fed with the dietcontaining $100 \mathrm{~g} / \mathrm{kg}$ quinoa seed meal. Group 3 birds were fed with $200 \mathrm{~g} / \mathrm{kg}$ quinoa seeds meal as a protein source. From day 21 to day 42 all birds from group 4 were fed with $50 \mathrm{~g} / \mathrm{kg}$ quinoa seed meal. Group 5 chicks were fed with the dietcontaining $100 \mathrm{~g} / \mathrm{kg}$ quinoa seeds meal and group 6 chicks were fed with diet contain quinoa seed meal $(200 \mathrm{~g} / \mathrm{kg})$ as a protein source. Control birds were fed with $100 \%$ commercially available feed. In results, significant effects of quinoa meal in the trial. 2 and trial3 improved kidney functions (ALT \& AST) and liver functions (Urea $\&$ Creatinine). The quinoa phytochemicals indicate major role as protein meal in the poultry feed through a multiplicity of effects.

Keywords: Kidney function; Liver function; Poultry; Quinoa

\section{Introduction}

Nutritive balanced feeding is most important for economic poultry production. Numerous feed additives used to increase poultry production including various drugs, but antibiotic-resistant and excessive use of drugs cause a variety of health risk to consumers [1]. Use of antibiotics in poultry feed as a growth promoter is reduced globally [2]. Scientist prefers natural plant-based 
meals because of its elevated crude protein content to be used as a potential animal feedstuff the nutritive content of plant seeds makes them an essential part of animal feed [3].

Phytobiotics originate from plants are proved to be excellent growth promoters [4]. Chemical composition revealed that quinoa seeds are a useful supply of protein, raw dietary fiberand calcium supplements [5]. Being gluten-free quinoa has health beneficial characteristics [6]. Quinoa has great nutritional value due to vitamins $(\mathrm{B}, \mathrm{C}$, and E) and lipids. In developing countries, quinoa has become a fashionable food, rather than other cereals [7]. Quinoa (Chenopodium quinoa) provide great alternatives to soybean as financial durability associated due to top quality proteins, macro as well as micronutrients because tend to be great causes of bioactive non-nutrient substances [8].

Quinoa with high nutritive contents might be suitable as livestock feed [9]. Quinoa seeds meal protect animals from oxidative stress by raising their antioxidant capacity and dropping lipid peroxidation in plasma and different tissues [10].

Quinoa attained high biological value due to the presence of lysine and sulphur containing amino acid and protein-rich quinoa contain excellent amino acid contents [11]. High levels of energy, calcium, iron, phosphorous, Vitamin E and Vitamin B are present in quinoa than corn, barley, wheat and oats [12].
Additionally, zinc and calcium are present inquinoa in high amount [13]. Quinoa body fat higher in $\alpha$-linoleic acid and an important omega 3 fatty acid, as compared to oat as well as soya natural oils. Due to its high inherited variability quinoa is not native to the Andes but also cultivated in Europe, North America, North Africa, Pakistan and China [14].

The current study was designed to observe the effects of quinoa seed as a partial protein source and its impact on broiler health by studying its effects on liver functioning, kidney functions as well as histological analysis of different organs (heart, lungs, kidney, and spleen) after feeding the birds with varying amounts of quinoa seeds meal.

\section{Materials and methods \\ Plant material}

Quinoa seeds meal were obtained from University of Agriculture, Faisalabad. Freshly harvested seeds were washed with distilled water and dried in the air for three to four days under the shed until constant weight in order to use as a protein source as partial protein replacement in the commercially available feed. Total 3 different meals prepared using quinoa seed meal as a protein source (Table 1). For trial 1 and trial $4(50 \mathrm{~g} / \mathrm{kg}$ quinoa seed meal partially replaced as a protein source). For trial 2 and trial $5(100 \mathrm{~g} / \mathrm{kg}$ quinoa seed meal used as the protein source). For trial 3 and trial 6 $(200 \mathrm{~g} / \mathrm{kg}$ quinoa seed meal used as the protein source) (Table 2).

Table 1. Diet composition for different groups for studying quinoa seeds effect

\begin{tabular}{|c|c|c|}
\hline Trials & Treatment Day & Quinoa seed as the protein meal replacement (\%). \\
\hline Group 1 & $14-42$ & $50 \mathrm{~g} / \mathrm{kg}$ \\
\hline Group 2 & $14-42$ & $100 \mathrm{~g} / \mathrm{kg}$ \\
\hline Group 3 & $14-42$ & $200 \mathrm{~g} / \mathrm{kg}$ \\
\hline Group 4 & $21-42$ & $50 \mathrm{~g} / \mathrm{kg}$ \\
\hline Group 5 & $21-42$ & $100 \mathrm{~g} / \mathrm{kg}$ \\
\hline Group 6 & $21-42$ & $200 \mathrm{~g} / \mathrm{kg}$ \\
\hline Control group & $1-42$ & $0 \%$ \\
\hline
\end{tabular}


Table 2. Quinoa seed meal feeding trials in different groups of the broiler

\begin{tabular}{|c|c|}
\hline Trials & Composition \\
\hline T.1 & $50 \mathrm{~g} / \mathrm{kg}$ quinoa seed meal partially replaced as a protein source \\
\hline T.2 & $100 \mathrm{~g} / \mathrm{kg}$ quinoa seed meal used as the protein source \\
\hline T.3 & $200 \mathrm{~g} / \mathrm{kg}$ quinoa seed meal used as the protein source \\
\hline T.4 & $50 \mathrm{~g} / \mathrm{kg}$ quinoa seed meal partially replaced as a protein source \\
\hline T.5 & $100 \mathrm{~g} / \mathrm{kg}$ quinoa seed meal used as the protein source \\
\hline T.6 & $200 \mathrm{~g} / \mathrm{kg}$ quinoa seed meal used as the protein source \\
\hline Controls & $100 \%$ commercially available feed \\
\hline
\end{tabular}

\section{Rearing of birds}

To study the dietary effects of quinoa seed meal on broiler 70 healthy chicks (one day old) were purchased from the hatchery. Chicks were kept in cages under controlled temperature. Sugar water $(5 \%)$ given to chicks on the weekly bases as an energy boost for the first two weeks. Rodents and pets were also kept away from chicks. The experiment went on for 42 days for all six trials as well as for control. Ten chicks were used for each experimental dietary group. One group was fed with commercially available poultry feed as control while other groups were fed with diet supplemented with quinoa seeds. Feed, water, and uniform light provided round the clock during the study period.To study the effects on liver functionandkidney functioning analysis all the birds were slaughtered at day forty-two (42) for the collection of blood.

\section{Blood collection}

From jugular vein of birds, almost $3 \mathrm{ml}$ of blood were taken from each bird. The blood samples of each bird were collected into two well-labeled sets of without anticoagulant vacutainers separately.

\section{Biochemical assay}

The blood samples without anticoagulant werein a centrifuged at $3,000 \mathrm{rpm}$ for 15 minutes and separated serum stored at $-10^{\circ} \mathrm{C}$ for further analysis. The serum was used for the estimation of biochemical constituents. Serum AST, ALT, Urea, Creatinine investigated withautomatic analyzer Microlab 300 (Merck®, Germany) available at Department of Poultry Science, the University of Agriculture Faisalabad.

\section{Statistical analysis}

The data was analyzed using GraphPadPrism 7 software (USA). Results were expressed as mean $\pm \mathrm{SD}$. One-way analysis of variance (ANOVA) followed by Dunnett post-test was used for analysis. The difference at $\mathrm{p}<0.05$ considered statistically significant.

\section{Results}

Effects of quinoa diet on broiler health the effects on Liver function and Kidney function studied and measured by estimating the levels of ALT and AST for liver function analysis. For kidney function analysis Urea and Creatinine test were performed.

Laboratory investigations of ALT (U/L)of chicks with different Quinoa seeds trials showed following trends as Trial $4(25.67 \pm 2)$ $>$ Control $(21.00 \pm 2)>$ Trial $1(17.67 \pm 3)>$ Trial $6(17.00 \pm 2)>$ Trial $5(14.33 \pm 3)>$ Trial $3(10.33 \pm 0.5)>$ Trial $2(8.667 \pm 1)$. Trial 4 showed the highest elevated level of ALT in comparison with other trials. Trial 2, Trial 3 and trial 5 were significant $(\mathrm{P} \leq 0.001)$ as compared to control samples. Trial 1, Trial 4 and trial 6 were nonsignificant $(\mathrm{P}>0.05)$ as compared with the control sample. Trial 2, Trial 3 and Trial 4 were significant $(\mathrm{P} \leq$ 0.001) in comparison with Trial 1 (Fig.1-a). Laboratory investigations of AST (U/L)level of chicks with different Quinoa seeds diets showed the following trends as Trial 4 (228.3 $\pm 37)>$ Trial $2(197.0 \pm 56)>$ Trial $1(184.0$ $\pm 47)>$ Trial $5(176.0 \pm 83)>$ Trial $6(166.7$ $\pm 15)>$ Trial $3(154.7 \pm 28)>$ Control $(141 \pm$ 
10.82). Trial 4 (In which the birds supplemented with $50 \mathrm{~g} / \mathrm{kg}$ quinoa seeds from day 21 to day 42) elevated the AST level in comparison with other trials (Fig.1-b).

Laboratory investigations of serum creatinine $(\mathrm{mg} / \mathrm{dl})$ of chicks fed with different Quinoa seeds meal showed different effects in following trends as Trial $4(1.2 \pm 0.1)>$ Trial $2(1.1 \pm 0.1)>$ Trial $1(1.0 \pm 0.1)>$ Trial 6 $(1.0 \pm 0.1)>$ Trial $5(0.9 \pm 0.1)>\operatorname{control}(0.9 \pm$ $0.1)>$ Trial. $3(0.9 \pm 0.2)$. Trial 4 showed the highest effect on broiler serum creatinine level as compared to other trials (Fig.1-c). Trial 4 exhibited most significant effect on serum creatinine level in comparison with other trials that showed non-significant $(\mathrm{P}>$ $0.05)$ in comparison with control sample (Fig.1-c).

Laboratory investigations of Urea (mg/dl)of broiler with different Quinoa seeds meal trials showed following trends Trial $4(45.00$ $\pm 5)>$ Control $(42.33 \pm 1)>$ Trial $1(41.00 \pm$ $3)>$ Trial $5(31.33 \pm 6)>$ Trial $6(31.33 \pm 1.5)$ $>$ Trial $2(30.33 \pm 3.512)>$ Trial $3(26.67 \pm$ 2.). Trial 4 showed the significant $(\mathrm{P}>0.05)$ level of serum urea in comparison with other trials (Fig. 1-d). (a)

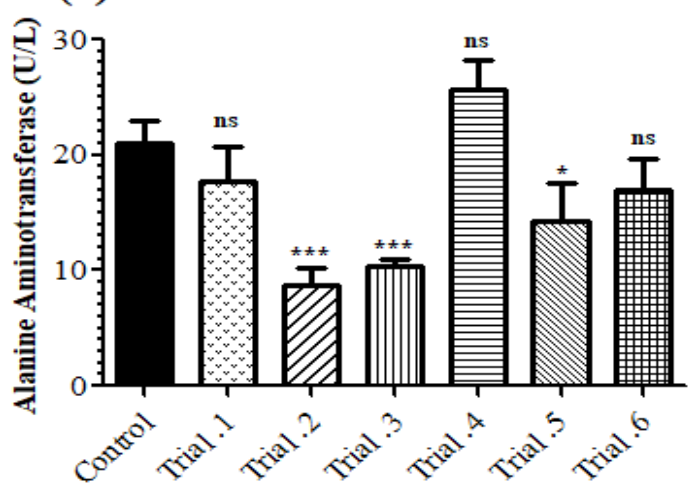

(c)

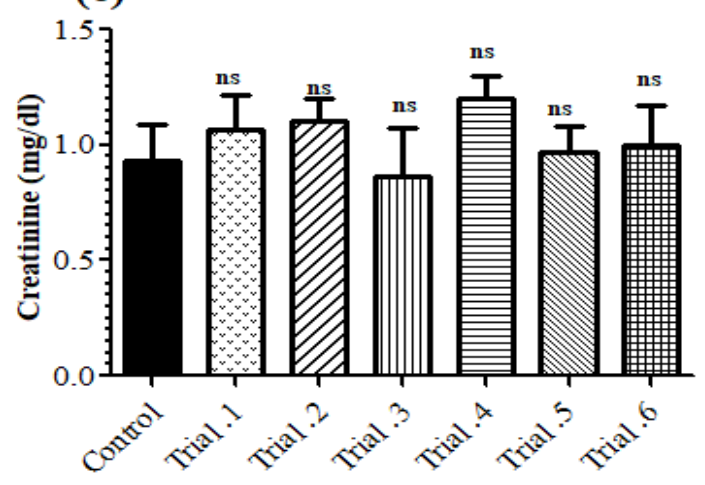

(b)

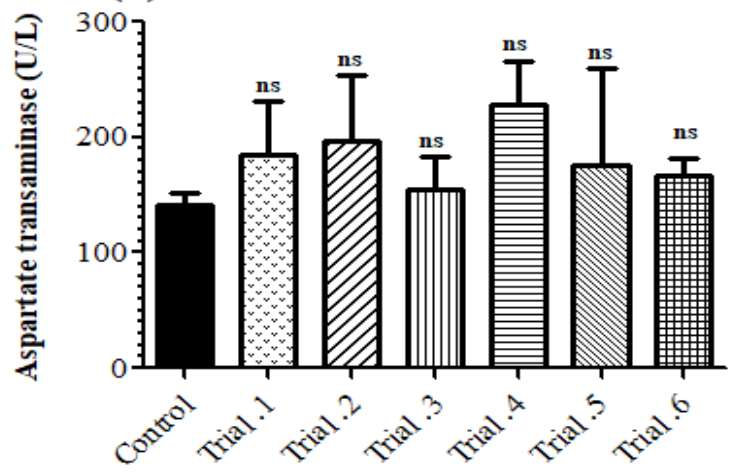

(d)



Figure 1. Showing the effects of quinoa seed meals on serum (a) Alanine Amino transferase (b) Asparate Aminotransferase (c) Creatinine (d) Urea level of broiler. Values were mean \pm SD of ten replicates. "Significant, ${ }^{* *}$ High significant, ${ }^{* * *}$ highly significant, ${ }^{\text {ns }}$ Not significant 


\section{Discussion}

The pseudocereal quinoa (Chenopodium quinoa) contains a high quantity health beneficial nutrients with protein contents (12$23 \%$ ), vitamin (B, C, and E), minerals such as (Iron, Zinc, Phosphorus and Potassium), fat content (7-9\%) and dietary fiber [10]. The current study was designed to investigate the effects of quinoa seeds as partial protein source on broiler health by studying its effects on liver and kidney functions measuring the level of AST, ALT, Creatine, and Urea after slaughtering the birds at day 42 to study the quinoa seeds effect as an alternative protein source of soybean meal for broiler feed. Studies reported the use of quinoa seeds as a potential nutrient for poultry feed. Quinoa seeds meal supplementation proved beneficial in trials using quantity less than $150 \mathrm{~g} / \mathrm{kg}$ [15].

ALT is a crucial enzyme in the biotransformation and detoxing numerous toxicants, reactive oxygen species as well as endobiotics and xenobiotics [16]. In the present study ALT level was not significantly elevated $(P>0.05)$ in trial 1 , trial 4 and trial 5 as compared to control. ALT level declined significant $(\mathrm{P}>0.05)$ in Trial 2, Trial 3 and trial 5. Our results showed non-significant $(\mathrm{P}$ $>0.05$ ) level of ALT in trial 6 in which birds were fed with $200 \mathrm{~g} / \mathrm{kg}$ quinoa seeds as protein source from day 21 to day 42 in comparison with control. According to results of ALT, our findings suggest that quinoa (Chenopodium quinoa) seeds as a partial replacement of protein supplement $(100 \mathrm{~g} / \mathrm{kg})$ is beneficial and save in use for broiler feed without deleterious effects. The use of Quinoa seeds more than $100 \mathrm{~g} / \mathrm{kg}$ in broiler feed affect blood biochemical parameters of broiler. In the present study non-significant high level of ALT was found among broiler showed an indication of muscular or liver damage. In our study, no abnormal elevation in the level of ALT enzyme was observed indicating that Quinoa as partial replacement of protein source can be implemented in broiler diet agreeing with Cruz et al. who reported the addition of quinoa seeds in broiler feed without any anti nutritional results [17].

AST used in liver function activity used to determine hepatocellular toxicity [18] but in the currentstudy, AST are not significantly ( $\mathrm{P}$ $>0.05$ ) affected by dietary treatments showed significant differences among the different treatment.

In the currentstudy, no hyperuricemia happens in birds due to quinoa and renal illness. The normal concentration of urea predicts the quality of protein in the diet. Any kind of modifications within proteins catabolism tends to be primarily associated with serum urea. In the present study significantly declined values of urea were found in trial 2 trial, trial 3, trial 5 and trial 6 chicks fed with quinoa seeds as the protein source compared to control. in our results, we did not observe any increase in reference value area in case of all treatments.

In the present study concentration of creatinine was not significant $(\mathrm{P}>0.05)$ among all broiler birds fed with $50 \mathrm{~g} / \mathrm{kg}$ quinoa seeds as partial protein source in trial 1. Serum creatinine level is a sign associated with proteins metabolic process, a byproduct of phosphocreatine break down within muscle cells [19] in currentstudy, creatinine level showed phosphocreatine break down within muscle cells.

In our results trial 1 and trial 4 showed highly significant values of all biochemical parameters in which the birds were fed with $50 \mathrm{~g} / \mathrm{kg}$ quinoa seeds as a protein source. According to our study on all biochemical parameters, our findings suggest that quinoa (Chenopodium quinoa) seeds as a protein supplement in quantity less than $100 \mathrm{~g} / \mathrm{kg}$ are beneficial and save in use for broiler feed with no deleterious effects on liver functions ALT and AST.Similarly, kidney functions Urea and Creatinine were also normal. 


\section{Conclusion}

In the currentstudy, we observed no harmful effects of quinoa supplemented meals on liver functions as AST and ALT level was in desirable range and kidney functions analysis of serum Urea and Creatinine were also in the normal range in which the birds were fed with different quinoa seeds meal as partial replacement of protein source. Trial 6 showed the absence of certain features and hemorrhagic areas in heart of trial 6 chick might be due to the high percentage of protein fed diet. Although no abnormalities were observed suggesting that quinoa (Chenopodium quinoa) seeds as a protein supplement in quantity less than $200 \mathrm{~g} / \mathrm{kg}$ are beneficial.

\section{Ethical approval}

All experimental trial approved by the ethical board of Government College University Women University Faisalabad, Pakistan and performed in accordance with relevant guidelines and regulations.

\section{Authors' contributions}

Conceived and designed the experiments: A Riaz, MS Masoud \& S Mustafa, Performed the experiments: S Mustafa \& Z Tariq, Analyzed the data: MA Riaz \& A Riaz, Contributed materials/ analysis/ tools: A Riaz \& M Ilyas, Wrote the paper: S Nazar, AU Haq, Z Sabir, A Riaz, MA Riaz \& M Ilyas.

\section{References}

1. Bidarkar VK, Swain PS, Ray S \& Dominic G (2014). Probiotics: Potential Alternative to Antibiotics in Ruminant Feeding. Trends Vet Anim Sci 1: 01-04.

2. Gordillo-Bastidas E, Díaz-Rizzolo DA, Roura E, Massanes T \& Gomis R (2016). Quinoa (Chenopodium quinoa Willd), from nutritional value to potential health benefits: an integrative review. J Nutr Food Sci 6: 10-4172.

3. Nisar M, More DR, Zubair S \& Hashmi SI (2017). Physico-chemical and nutritional properties of quinoa seed: A review. J Pharmacogn Phytochem 6: 2067-2069.

4. Wallace R J, Oleszek W, Franz C, Hahn I, Baser KHC, Mathe A \& Teichmann, K (2015). Dietary plant bioactives for poultry health and productivity. Br Poult Sci 1: 461-487.

5. Satheesh N \& Fanta SW (2018). Review on structural, nutritional and antinutritional composition of Teff (Eragrostistef) in comparison with Quinoa (Chenopodium quinoa Willd.). Cogent Food Agric 4: 1-27.

6. Laus M N, Gagliardi A, Soccio M, Flagella Z \& Pastore D (2012). Antioxidant activity of free and bound compounds in quinoa (Chenopodium quinoa Willd.) seeds in comparison with durum wheat and emmer. J Food Sci 77: 1150-C1155.

7. Vilcacundo R \& Hernández-Ledesma B (2017). Nutritional and biological value of quinoa (Chenopodium quinoa Willd.). CurrOpin Food Sci 14: 1-6.

8. Pihlanto A, Mattila $\mathrm{P}$, Mäkinen $\mathrm{S} \&$ Pajari AM (2017). Bioactivities of alternative protein sources and their potential health benefits. Food Funct 3443-3458.

9. Vega-Galvez A, Miranda M, Vergara J, Uribe E \& Puente I (2010). Nutrition facts and functional potential of quinoa (chenopodium quinoa willd) an ancient Andean grain. A review. J Sci Food Agric 90: 2541-2547.

10. Navruz-Varli S \& Sanlier N (2016). Nutritional and health benefits of quinoa (Chenopodium quinoa Willd.). J Cereal Sci 69: 371-376.

11. James LEA (2009). Quinoa (Chenopodium quinoa Willd.): composition, chemistry, nutritional, and functional properties. Adv Food Nutr Res 58: 1-31. 
12. Vilche C, Gely M \& Santalla E (2003). Physical properties of quinoa seeds. Biosyst Eng 86: 59-65.

13. Konishi $\mathrm{Y}$, Hirano $\mathrm{S}$, Tsuboi $\mathrm{H} \&$ Wada M (2004). Distribution of minerals in quinoa (Chenopodium quinoa Willd.) seeds. Biosci Biotechnol Biochem 68: 231-234.

14. Zurita-Silva A, Fuentes F, Zamora P, Jacobsen SE \& Schwember AR (2014). Breeding quinoa (Chenopodium quinoa Willd.): potential and perspectives. $\mathrm{Mol}$ Breed 34: 13-30.

15. Graf BL, Cheng D M, Esposito D, Shertel T, Poulev A, Plundrich N \& Raskin I (2015) . Compounds leached from quinoa seeds inhibit matrix metalloproteinase activity and intracellular reactive oxygen species. Inter J Cosmet Sci 37: 212-221.

16. Odunsi AA, Rafiu TA, Olaniyi CO \& Binuomote RT (2013). Growth and serological assessment of broiler chickens fed differently processed castor (Ricinus communis Linn.) kernel cake based diets. Afr J Agric Res 8: 51615165.

17. Cruz CEB, Freitas ER, Braz NDM, Salles RPR \&Silva INGD (2018). Blood parameters and enzymatic and oxidative activity in the liver of chickens fed with calcium anacardate. Revista Ciência Agronômica 49: 343-352.

18. Ojiezeh TI, \& Ophori EA (2015). Haemogram and serum enzymes activities of Newcastle disease virus challenged broiler chickens following supplemental treatment with aloe vera extract. J Clin. Cell Immunol 6: 282.

19. Szabó A, Mezes M, Horn P, Sütő Z, Bázár GY \& Romvari R (2005). Developmental dynamics of some blood biochemical parameters in the growing turkey (Meleagris gallopavo). Acta Vet Hung 53: 397-409. 